\title{
artigo
}

\section{Função Materna em Mulheres com Filho Pré-Termo Hospitalizado em Unidade Neonatal}

\author{
Maternal Function in Women with Pre-Term Child in Neonatal Unit \\ Función materna en mujeres con niño pretérmino hospitalizadas en unidad neonatal
}

\begin{abstract}
RESUMO
O nascimento prematuro pode interferir na relação mãe-bebê, com riscos de instaurar falhas psíquicas. Objetivo: Analisar como a função materna pode ser afetada pelas condições do nascimento prematuro do bebê e pelo itinerário terapêutico em unidade neonatal de referência para o Método Canguru. Método: Participaram 06 mães de bebês pré-termos, através de entrevistas abertas, utilizando os operadores conceituais dos Indicadores Clínicos de Risco para o Desenvolvimento Infantil (IRDI) como norteadores. $O$ estudo foi submetido ao Comitê de Ética, de acordo com as Resoluções 466/12 e 510/16. Resultados: Duas categorias temáticas emergiram da Análise de Conteúdo: "Repercussões da prematuridade na subjetividade materna" e "Sobre o tempo e redes de apoio". O tempo de espera na hospitalização do filho pré-termo repercutiu para a mãe como um tempo de reelaboração psíquica. Conclusão: A rede de apoio e a transferência atenuaram os entraves instaurados na relação mãe-bebê, protegendo a saúde mental materno-infantil.
\end{abstract}

DESCRITORES: Pré-termo; Psicanálise; Unidades de Terapia Intensiva Neonatal.

\section{ABSTRACT}

Prematurity of birth can interfere in the mother's relationship with her baby, with risks of establishing psychic failures. So, this research sought to analyze how the maternal function can be affected by the conditions of premature birth of the baby and by the therapeutic itinerary in a neonatal referral unit for the Kangaroo Method. 06 mothers of preterm babies participated. Open interviews were conducted, using the conceptual operators of the protocol axes of the Research on Clinical Risk Indicators for Child Development (IRDI) as guides.The study was submitted to the Ethics Committee in resolution 466/12. In content analysis, the following thematic categories emerged: "Repercussions of premature birth in the mother's subjectivity" and "About time and support networks". It was understood that the waiting time for the hospitalization of the preterm child can work for the mother as a time for psychic re-elaboration. The support networks and transfer attenuared the obstacles established in the mother-infant relationship, thus protecting maternal-infant mental health.

DESCRIPTORS: Pre-Term; Psychoanalysis; Intensive Care Units.

\section{RESUMEN}

La prematuridad al nacer puede interferir en la relación de la madre con su bebé, con riegos de establecer fallas psíquicas. Entoces, esta investigación trató de analizar cómo la función materna puede verse afectada por las condiciones del parto prematuro del bebé y por el itinerario terapéutico en una Unidad Neonatal de referencia para el Método Canguro. Participaron 06 madres de bebés prematuros. Se realizaron entrevistas abiertas, utilizando los operadores conceptuales de los ejes del Protocolo de Investigación. Indicadores de Riesgo para el Desarrollo Infantil (IRDI) como guías. El estudio fue presentado al Comité de Ética, de acuerdo con la resolución 466/12. En el análisis de contenido, surgieron las se siguientes categorías: "Repercusiones de la prematuridad en la subjetividad materna" y "Sobre el tiempo y las redes de apoyo". Fue entendió, que el tiempo de espera para la hospitalización del hijo prematuro, puede funcionar para su madre como un tiempo de relaboración psíquica. Las redes de apoyo y la transferencia alliviaron los obstáculos establecidos en la relación madre-hijo, protegiendo así la salud mental materno-infantil.

DESCRIPTORES: Prematuro; Psicoanálisis; Unidades de Cuidados Intensivos Neonatales.

RECEBIDO EM: 04/06/2021 APROVADO EM: 14/06/2021

\section{Danielle Barbosa Maciel de Souza Teixeira}

Mestre em Psicologia da Saúde pela Faculdade Pernambucana de Saúde, Recife, Pernambuco, Brasil.

ORCID: 0000-0003-1603-5569 


\section{Tathyane Gleice da Silva Lira}

Mestre em Psicologia pela Universidade Federal de Pernambuco. Docente da graduação e pós-graduação em Psicologia da Faculdade Pernambucana de Saúde, Recife, Pernambuco, Brasil.

ORCID: 0000-0002-2416-8436

\section{Clarissa Maria Dubeux Lopes Barros}

Doutora em Psicologia Social pela Universidade Federal da Paraíba. Docente da graduação em Psicologia e do Mestrado em Psicologia da Saúde Faculdade Pernambucana de Saúde, Recife, Pernambuco, Brasil.

ORCID: 0000-0003-4790-8203

\section{INTRODUÇÃO}

A $s$ descobertas a respeito do cuidado humanizado ao bebê pré-termo tiveram efeito direto na transformação das unidades neonatais brasileiras. O estilo biomédico tradicional tornou-se ineficaz à promoção da saúde no começo da vida. A interprofissionalidade e os novos protocolos de cuidado valorizaram as singularidades do bebê, tornando o ambiente hospitalar mais acolhedor, ainda que, em alguns casos, longe do ideal. ${ }^{1}$

Independente de nascer prematuro, todo bebê humano está imerso no desamparo psíquico ao nascer. Depende de um adulto que desempenhe os cuidados básicos e supra suas necessidades. Porém, ainda que totalmente dependente, o bebê não é totalmente passivo. Desde a vida intra-uterina, ele tem competência para interagir e captar informações do ambiente. Nasce com predisposição ao contato com o outro e com particularidades físicas que lhe servem de base para sua constituição psíquica. Seu repertório biológico e sua apetência ao afeto qualificam suas respostas ao mundo externo. Assimila e interpreta as experiências com as pessoas ao redor, sendo ativo nas relações que estabelece. ${ }^{2}$

Para o bebê vir a se constituir enquanto sujeito e a se estruturar subjetivamente, é preciso que alguém invista expectativas, desejos e sonhos nele e para o mesmo, supondo ali uma possibilidade de futuro. Esse investimento primordial organiza psiquicamente o bebê, faz uma antecipação subjetiva, posicionando-o como um sujeito a advir. É necessário haver alguém que se lance nessa empreitada de fazer função materna para o bebê. . $^{1,34}$

Um modo de observar o estabelecimento dessa relação afetiva entre o bebê
Para o bebê vir

a se constituir enquanto sujeito

e a se estruturar subjetivamente, é preciso que alguém invista expectativas, desejos e sonhos nele e para o mesmo, supondo ali uma possibilidade de futuro. Esse

investimento

primordial organiza

psiquicamente

o bebê, faz uma

antecipação subjetiva,

posicionando-o como

um sujeito a advir. sua mãe, é através dos quatro eixos que norteiam os Indicadores Clínicos de Risco para o Desenvolvimento Infantil (IRDI): suposição de sujeito, estabelecimento de demanda, alternância presença-ausência e função materna. ${ }^{5}$ Eles resumem as operações de constituição psíquica, por testemunharem os efeitos das inscrições das marcas impressas no corpo do bebê, pelo Outro cuidador. Por isso, serviços públicos de saúde têm dado atenção a esses eixos, que servem de metodologia científica de promoção de saúde. ${ }^{6}$

Eles são salutares para se pensar a relação mãe - bebê pré-termo. A chegada de deste bebê hospitalizado traz implicações no desempenho da função materna. A mãe pode experimentar dificuldades psíquicas que interferem na sua identificação com seu bebê, haja vista as exigências que ele lhe coloca. Ao nascer, ele é retirado de sua mãe, necessitando de intervenções interprofissionais. A mãe fica dominada por um sentimento de culpa devastador, diante do seu "bebê moribundo. E pode vir a rivalizar com a equipe, que tem um saber sobre o bebê do nascimento à alta hospitalar. Tais vivências delineam o trauma e a urgência do começo da vida, dificultando aceitar o bebê da realidade. ${ }^{1,3,7}$

$O$ bebê segue um percurso terapêutico árduo e inconstante nas etapas de cuidado da unidade neonatal. Sobrevém um tempo de crise, através do qual bebê e família estão suscetíveis a riscos psíquicos. ${ }^{8}$ Para preservar a função materna, pois, o psiquismo do bebê, devem existir intervenções que permitam ao bebê e à mãe se "fabricarem" como tais. ${ }^{7}$

Na unidade neonatal, a Psicanálise propõe escutar os bebês, mas primeiro facilitar que o sofrimento das mães seja posto em palavras, simbolizando o encontro fal- 
toso. A escuta psicanalítica é facilitadora, para que a paralisação diante das vicissitudes na unidade neonatal dê lugar ao tempo de compreender, ao tempo de luto e ao tempo de ressignificar. ${ }^{1}$

Portanto, o objetivo desta pesquisa foi analisar como a função materna pode ser afetada pelo nascimento prematuro e pelo itinerário terapêutico do bebê em unidade neonatal.

\section{MÉTODO}

Participaram mães de filho pré-termo internado em unidade neonatal de referência. Inicialmente, seu bebê estava na primeira etapa de cuidados, na Unidade de Terapia Intensiva Neonatal (UTIN) ou na Unidade de Cuidado Intermediário Neonatal Convencional (UCINCo). A pesquisa seguiu até irem à Unidade de Cuidado Intermediário Neonatal Canguru (UCINCa), configurando uma trajetória terapêutica hospitalar.

A pergunta disparadora da entrevista aberta e audiogravada foi: "Como é para você ter tido um parto prematuro e ter seu filho internado em uma unidade neonatal?" No manejo da entrevista, o IRDI foi usado como referencial para interpretar as narrativas maternas.

As transcrições das entrevistas passaram pela Análise Temática, interpretando-se o conteúdo latente das falas e suas significações atribuídas. ${ }^{9} \mathrm{E}$ a teoria psicanalítica serviu de lente interpretativa, incluindo os eixos do IRDI e aspectos de cunho transferencial.

A pesquisa foi aprovada pelo Comitê de Ética sob parecer $n^{\circ} 2.457 .357$ e as mães assinaram o Termo de Consentimento Livre e Esclarecido.

\section{RESULTADOS E DISCUSSÃO}

A análise das entrevistas de 06 mães, Margarida, Bromélia, Violeta, Tulipa, Orquídea e Girassol (nomes fictícios) gerou as categorias temáticas: 1) Repercussões do nascimento prematuro na subjetividade da mãe; 2) Sobre o tempo e as redes de apoio.

\section{1) Repercussões do nascimen- to prematuro na subjetividade da mãe:}

Sobre o nascimento prematuro do filho, a fragilidade do corpo dele e sua hospitalização, as mães expressaram desespero, medo e surpresa:

"Eu nem imaginava que ia ter um filho prematuro (...) Eu fiquei desesperada." (Violeta); "Porque a bolsa rompeu, [senti] muito medo." (Margarida); "Quando eu vi, nossa, muito pequenininha. (...) Chorei, porque eu não esperava que seria desse jeito. (...) Achei que não iria sobreviver." (Bromélia)

Estudos demonstram que algumas mães se sentem confusas, cheias de culpa e se questionam se poderiam ter evitado o nascimento prematuro. Esse primeiro impacto ao ver o bebê na UTIN pode ser vivido como traumático e prejudicial à formação de vínculos. ${ }^{10,11,12}$

Para algumas mães, tais reações emocionais devastadoras eram uma reedição de perdas anteriores:

"Porque eu já tinha perdido um, que nasceu morto né, (...) [senti] muito medo [...] de nascer morto de novo, né." (Margarida)

Entretanto, a história anterior poderia estar à serviço de uma narratividade producente. O primeiro pré-termo de Tulipa sobreviveu: a repetição da prematuridade, ainda que ferisse o narcisismo dessa mulher, também a fortalecia, como uma centelha para apostar no novo filho. O segundo trauma despertou a vitória anterior, o primeiro trauma tornou-se recurso de reparação: $:^{12,13}$

"Foi assim um pouco mais tranquilo, porque eu já tenho uma menina, que também foi prematura (...) já sabia de tudo um pouco né, aí foi mais tranquila..."(Tulipa).
Tulipa anunciou um saber sobre a realidade vivida. Ao supor um saber, provava de uma cota indispensável de "tranquilidade", minorando angústias e fantasias. Interessante observar, esse bebê era sufocante ("chorão", "brabo", "nervoso"), transmitindo à sua mãe queixas de um ambiente hostil. Sendo chorão, ele endereçava um apelo, dizendo de sua dificuldade em ocupar seu lugar, à procura de que ela o protegesse das excitações externas desorganizadoras. Outra vez, encorajada por seu lado melhorado, permitiu-se cativar pelo sorriso do neném, interpretando-o, e o pré-termo teve competência para parentalizar sua mãe, como se tivesse entendido perfeitamente a mensagem dela. ${ }^{13,14,16}$

Estudos comprovam que os bebês e suas mães são capazes de regularar mutuamente os sentimentos, através de seus rítmos próprios, utilizando trocas de sinais multimodais e imitações faciais, vocais e gestuais, e que mesmo em um contexto de nascimento prematuro, o bebê pode demonstrar o mesmo desejo de protoconversação, através de trocas de expressões faciais, vocalizações ou gestos com ritmo e percepção investigativa. Nessa dialética, a mãe garantia a pessoalidade ao bebê; na urgência, ela salvava a vida dele: ${ }^{14,16,17,18}$

\section{"O jeitinho dele, além da brabeza, que ele gosta que converse com ele, é bem sorridente". (Tulipa)}

Nessa investidura matera, elas localizavam um lugar subjetivo para o filho, mesmo que o futuro dele fosse pressentido como incerto. Narrava-o como "melindroso" e "caixinha de surpresa", tomadas pelo medo de perder sua cria. Destarte, esses significantes humanizavam os bebês, e eram ofertadas como vitais: $1,4,5,6,7$

\section{“Graças a Deus, tá vivo, né!.” (Mar- garida)}

Foram palavras que rodearam as incubadoras. Imersos na constante ameaça de aniquilamento, de toda sorte, os bebês receberam um lugar possível na subjetivação materna. ${ }^{13}$ Detectou-se que eles - su- 
posto sujeito a advir - apontavam para os qualificadores que as mães identificaram neles. O bebê vai tecendo suas impressões e construindo seu saber a partir de uma capacidade multimodal de interpretação do mundo e da relação com o outro. E os organizadores psíquicos - voz, olhar e toque favoreciam o estabelecimento da função materna: $3,4,6,17$

"2uando você começa a pegar seu bebê, (...) a recuperação dele é mais rápida(...) Ela já ouve minha voz, (...) vejo ela já (...) escutando, levantando os olhos, [...]chupando as mãos com fome." (Orquídea)

A sincronia também parece estar envolvida na co-regulação desses estados afetivos; isto é, seria um processo onde mãe e bebê durante as interações, combinam os estados afetivos um do outro, como em um dueto, onde mãe e filho vão entrando em sintonia a partir de cada experiência de troca. ${ }^{16,17,18}$

Dessa maneira, elas falaram de seu desejo materno, impactadas pelo horror da prematuridade e enquanto Outro Primordial, antecipavam uma existência para o bebê, inscrevendo as primeiras marcas subjetivas no corpo deles, banhando-os de linguagem. E na formação de seus rearranjos psíquicos, sentindo-se parte importante na recuperação de seu filho, à espera do tempo de levá-lo para casa; foi notável a função da rede de apoio.

\section{2) Sobre o Tempo e as Redes de Apoio}

O tempo de hospitalização do pré-termo é um período de crise ${ }^{8}$, com efeito na subjetividade das mães. Foi preciso um tempo cronológico, mas também um tempo subjetivo, para seus rearranjos psíquicos diante do trauma da prematuridade. ${ }^{3}$ Prematuramente mães, elas precisavam de um tempo de gestão de sua relação afetiva com o bebê da realidade. Ao seu estilo singular, suportaram a falta imposta pelo real do internamento do bebê. $\mathrm{O}$ tempo vivido no hospital foi ressignificado, ao absorverem uma espécie de aprendizado necessário. Depois disso, sentiram-se capacitadas a maternar seu filho, mesmo inseguras perante a crueza da vivência temporal de hospitalização do bebê:

"A rotina de ter [...] um dia de glória, de vitórias e outro dia não, nem sempre vai acontecer o que a gente quer". (Bromélia) Aos poucos, vivenciavam uma aceitação e um aprimoramento de si: "Não sei se é por conta do tempo,(...) comecei a aceitar (...) que tinha que ser assim [...] Amadurecer".(Girassol)

\section{Seu corpo orgânico}

\section{flagelado não}

\section{se normatiza na}

temporalidade

cronológica dos

pais. E o perigo

se instaura no

imperativo da pressa.

O bebê pré-termo hospitalizado está posto no destempo. Seu corpo orgânico flagelado não se normatiza na temporalidade cronológica dos pais. E o perigo se instaura no imperativo da pressa. Mães desorganizadas emocionalmente podem fixar o imperativo da acusação, nomeando-os de atrasados, queixosas do corpo débil, que não responde aos procedimentos médicos, no mesmo ritmo do tempo da realidade que se esvai. ${ }^{3,10}$ Sensível a um tempo que não é dela, Orquídea não padeceu nesse destempo, aceitou a variabilidade neurofisiológica do bebê. Singularizado, ele deixou de só ter que produzir no tempo que se espera dele: deparou-se com a demanda materna (ganhar peso, mamar, respirar sem aparelhos), mas conhe- ceu uma mãe atenta às suas necessidades, convocando-o a superar a indiferenciação orgânica ${ }^{14}$ :

"Eu tô aprendendo a ter paciência, porque o tempo não é o meu (...), eu tenho que aprender a esperar o tempo dela." (Orquídea)

Para que a mãe consiga investir nesse filho fragilizado pela prematuridade de sua chegada, é indispensável trabalhar o luto, a perda e a separação do filho idealizado. Essa é uma possibilidade interventiva para que a mãe consiga projetar para seu bebê pré-termo um futuro possível, um projeto vivo. Nesse sentido, o tempo de hospitalização pode ser capaz de permitir à mãe um trabalho de reparar sua própria imagem, autorizando-a a se tornar mãe para seu filho. ${ }^{3,7,10} \mathrm{O}$ exercício da função materna foi facilitado também pelo fato delas se sentiram apoiadas pela equipe de saúde, ao longo do itinerário terapêutico do bebê da UTIN/UCINCo à UCINCa. ${ }^{19,20}$ :

"(As enfermeiras) sempre vão aconselhando você assim, lhe acalmando." (Orquidea). "Graças a Deus, todas as residentes, as médicas que estão com ele, (...) [estão] sempre me apoiando, sempre apoiando ele." (Girassol)

Essa rede de apoio se estendia ao seu vínculo com outras mães da unidade, nutrindo sentimentos de autoconfiança, realização pessoal e dedicação ao bebê ${ }^{10,11,15,19,20}$

"Pelo que a gente passa aqui, (...) a gente precisa de um conforto, tem (mães) que está mais próxima de você e dá uma palavra de conforto. Como eu também posso dar, isso ajuda." (Bromélia)

Profissionais de saúde e outras mães assumiram a função de terceiro continen$\mathrm{te}^{11,20}$. Eles mediaram e contextualizaram a relação mãe-bebê, protegendo um do outro de suas fantasias mortíferas. ${ }^{1}$ Ao se 


\section{artigo}

sentirem cuidadas como mulheres-mães, falaram de conforto, ajuda, conselho e apoio para consigo; notaram o cuidado humanizado com o bebê; sem que percebessem, também estavam atravessadas pelas transferências organizadoras:

"Sinto (...) segura em relação aos cuidados que eles tão dando e ele" (Violeta); "Aqui (...) é o hospital que (...) os prematuros têm chance de sobreviver, (...) porque é um hospital indicado." (Orquídea)

A ressignificação do tempo vivido, a função mediadora da rede de apoio e a relação transferencial com a unidade auxilia- ram essas mulheres a fazerem reparação de sua própria imagem, autorizando-se como mãe para seu filho. ${ }^{3,7,11,14,20}$

\section{CONCLUSÃO}

Ao analisar como a função materna se estabelecia na unidade neonatal, notou-se a manifestação do desejo materno desafiando a incubadora. Mesmo com medo de perder o filho, ao perceber a fragilidade real do corpo nascido prematuro, as mães antecipavam seus bebês, dando-lhes um lugar subjetivo. O tempo de internação e o suporte da rede de apoio hospitalar (profissionais e outras mães) geraram algo criativo: as mães autorizaram-se a um saber inconsciente sobre seu filho. Ainda que a realidade se norteara por fatores de risco à saúde mental delas, esses fatores oportunazaram sua reelaboração psíquica. Contrabalançadas com os riscos, as transferências conceberam fatores de proteção para a saúde mental materno-infantil. Então, cabe ao psicanalista escutar essas mulheres e ler as produções corporais de seus bebês, facilitando a elaboração do trauma e reconhecer o potencial maternante delas. Contudo, é preciso que a equipe de saúde se implique na relação de cuidado, amparando essa mãe, para que se trace uma via de promoção à saúde materna e de prevenção psíquica para o bebê, que se encontra em estado de pré-venir.

\section{REFERÊNCIAS}

1. Rabello AM. Construção subjetiva e prematuridade na UTI Neonatal. Primórdios [internet] 2016. [acesso em 13 de julho de 2017]; 4(4):13-24 Disponivel em: http://cprj.com.br/primordios/04/2_Primordios_MioloVol4_Prova03-4.pdf

2. Parlato-Oliveira E, Szejer M, organizadores. O bebê e os desafios da cultura. São Paulo: Instituto Langage; 2019.

3. Jerusalinsky J. Enquanto o futuro não vem; a psicanálise na clínica interdisciplinar com bebês. Salvador: Ágalma; 2002.

4. Catão I. O bebê nasce pela boca: Voz, sujeito e clínica do autismo. São Paulo: Instituto Langage; 2009.

5. Jerusalinsky J. A Criação da criança: brincar, gozo e fala entre mãe e o bebê. Salvador: Àgalma; 2014.

6. Mariotto RMM, Pesaro ME. O roteiro IRDI: sobre como incluir a ética da psicanálise nas políticas públicas. Estilos da Clínica [internet] 2018. [acesso em 03 de junho de 2021]; 23 (1): 99113. Disponivel em: https://doi.org/10.11606/issn.1981-1624. v23i1p99-113

7. Mathelin C. O sorriso da Gioconda. Clínica psicanalítica com os bebês prematuros. Rio de Janeiro: Companhia de Freud; 1999.

8. Ministério da Saúde. Atenção Humanizada ao Recém-nascido Método Canguru: Manual Técnico. Brasília: Ministério da Saúde; 2017.

9. Gil AC. Métodos e Técnicas de Pesquisa Social. 7. ed. São Paulo: Atlas; 2019.

10. Arnold L, Sawyer A, Rabe H, Abbott J, Gyte G, Duley L, Ayers S; 'Very Preterm Birth Qualitative Collaborative Group'. Parents' first moments with their very preterm babies: a qualitative study. BMJ Open. 2013 Apr 2;3(4):e002487. doi: 10.1136/bmjopen-2012-002487. PMID: 23550091; PMCID: PMC3641451.

11. Fernandes, RT et al. Tecendo as teias do abandono: além das percepções das mães de bebês prematuros. Ciência e Saúde Co- letiva, n.16, v.10, p 4033-4042, 2011. https://doi.org/10.1590/ S1413-81232011001100008

12. Donelli TMS, O parto no processo de transição para a maternidade. Unpublishedmasther'sthesis, Programa de Pós-graduação em Psicologia do Desenvolvimento, Instituto de Psicologia, Universidade Federal do Rio Grande do Sul. Porto Alegre, Brasil, 2003.

13. Szejer M. Se os bebês falassem. São Paulo: Langage; 2016.

14. Laznik MC, Cohen, organizadores. O bebê e seus intérpretes: clínica e pesquisa. São Paulo: Instituto Langage; 2011.

15. Maldonado MT. Psicologia da gravidez. São Paulo: Ideias e Letras; 2017

16. Trevarthen, Colwyn; Aitken, Kenneth.; Gratier, Maya / O bebê, nosso professor - São Paulo: Instituto Langage, 2019.

17. Parlato-Oliveira E / Saberes do bebê - São Paulo: Instituto Langage, 2019.

18. Delaherche $E$, Chetouani M, Mahdhaoui A, Saint-Georges C, Viaux S, \& Cohen D (2012). Sincronia interpessoal: Um levantamento dos métodos de avaliação entre as disciplinas. IEEE Transactions on Affective Computing , 3 (3), 349-365.

19. Morsch DS, Braga NB. A depressão na gestação e na UTI Neonatal: In: Morsch DS, Braga NB. Quando a vida começa diferente: o bebê e sua família na UTI Neonatal. Rio de Janeiro: Fiocruz; 2003. [online]. Rio de Janeiro: Editora FIOCRUZ, 2003. Criança, Mulher e Saúde collection. 192 p. ISBN 978-85-7541357-9. Available from SciELO Books <http://books.scielo.org>.

20. Silva, R. S. da ., Barbosa, M. O. ., Teixeira, P. da C. ., Silva, G. Q. da ., Oliveira, P. P. ., Koeppe, G. B. O. ., \& Rocha, J. R. C. . (2020). Humanização na Unidade de Terapia Neonatal: percepção das mães. Saúde Coletiva (Barueri), 9(50), 1814 - 1822. Recuperado de http://revistas.mpmcomunicacao.com.br/index.php/saudecoletiva/article/view/163 